\title{
Ebelik Öğrencilerinin Mobil Telefon Yoksunluğu Korkusu ile Sosyal Destek Algısı Arasındaki İlişkinin İncelenmesi
}

\author{
Yasemin Aydin Kartal \\ Sağlık Bilimleri Üniversitesi Ebelik Bölümü İstanbul, Türkiye \\ email: yasemin.aydin@sbu.edu.tr \\ Orcid: 0000-0001-7464-945X \\ *Sorumlu Yazar / Corresponding Author: Sorumlu Yazar: Yasemin Aydın Kartal \\ Gönderim Tarihi / Received: 01.08.2019 \\ Kabul Tarihi / Accepted: 23.12.2019 \\ DOI: $10.34087 /$ cbusbed.600130
}

\begin{abstract}
Amaç: Bu çalışmada, mobil telefondan yoksun kalma korkusunun (nomofobi) ebelik öğrencileri arasında yaygınlığı ve sosyal destek algısı arasındaki ilişkinin incelenmesi amaçlanmıştır.

Yöntem: Tanımlayıcı desende yürütülen çalışmanın evrenini, bir kamu üniversitesinin Sağlık Bilimleri Fakültesi Ebelik Bölümü birinci ve ikinci, üçüncü sınıfında öğrenim gören öğrenciler oluşturdu. Çalışmada örneklem seçimine gidilmemiş olup çalışmaya katılmayı kabul eden 165 öğrenci çalışmanın örneklemini oluşturdu (Katılım Oranı:\%69,6). Veriler, araştırmacılar tarafından olușturulan “Tanıtıcı Bilgi Formu”, Nomofobi Ölçeği (NMP-Q)" ve "Çok Boyutlu Algılan Sosyal Destek Ölçeği(ÇBASDÖ)" kullanılarak toplanmıştır. Verilerin değerlendirilmesinde ortalama, standart sapma, sayı, yüzdelik, bağımsız örneklem t-testi, tek yönlü varyans analizi (ANOVA) kullanıldı. Bulgular: Ebelik öğrencilerinin NMP-Q toplam puan ortalamas1 75.22 \pm 22.21 , ÇBASDÖ toplam puan ortalamas1 ise $68.07 \pm 12.75$ olarak saptanmıștır. Calıșmaya katılan öğrencilerin orta düzeyde nomofobik oldukları belirlenmiştir. Ebelik öğrencilerinin mobil telefon yoksunluğu korkusu ile aileden algılanan sosyal destek arasında zayıf ve negatif yönlü anlamlı bir ilişki saptanmıştır. Sınıf düzeyi ve kalınan yer değişkenine göre nomofobinin farklılaştı̆̆ı belirlenirken, ebeveyn eğitim durumu ve gelir durumu değişkenlerine göre nomofobi düzeyinin farklılaşmadığı belirlenmiștir.
\end{abstract}

Sonuç: $\mathrm{Bu}$ bulgular doğrultusunda, çalışmaya katılan ebelik öğrencilerinde algılanan sosyal destek arttıkça mobil telefondan yoksun kalma korkusunun azaldığ 1 söylenebilir.

Anahtar Kelimeler: Ebelik Öğrencileri, Nomofobi, Akıllı Mobil Telefon, Sosyal Destek.

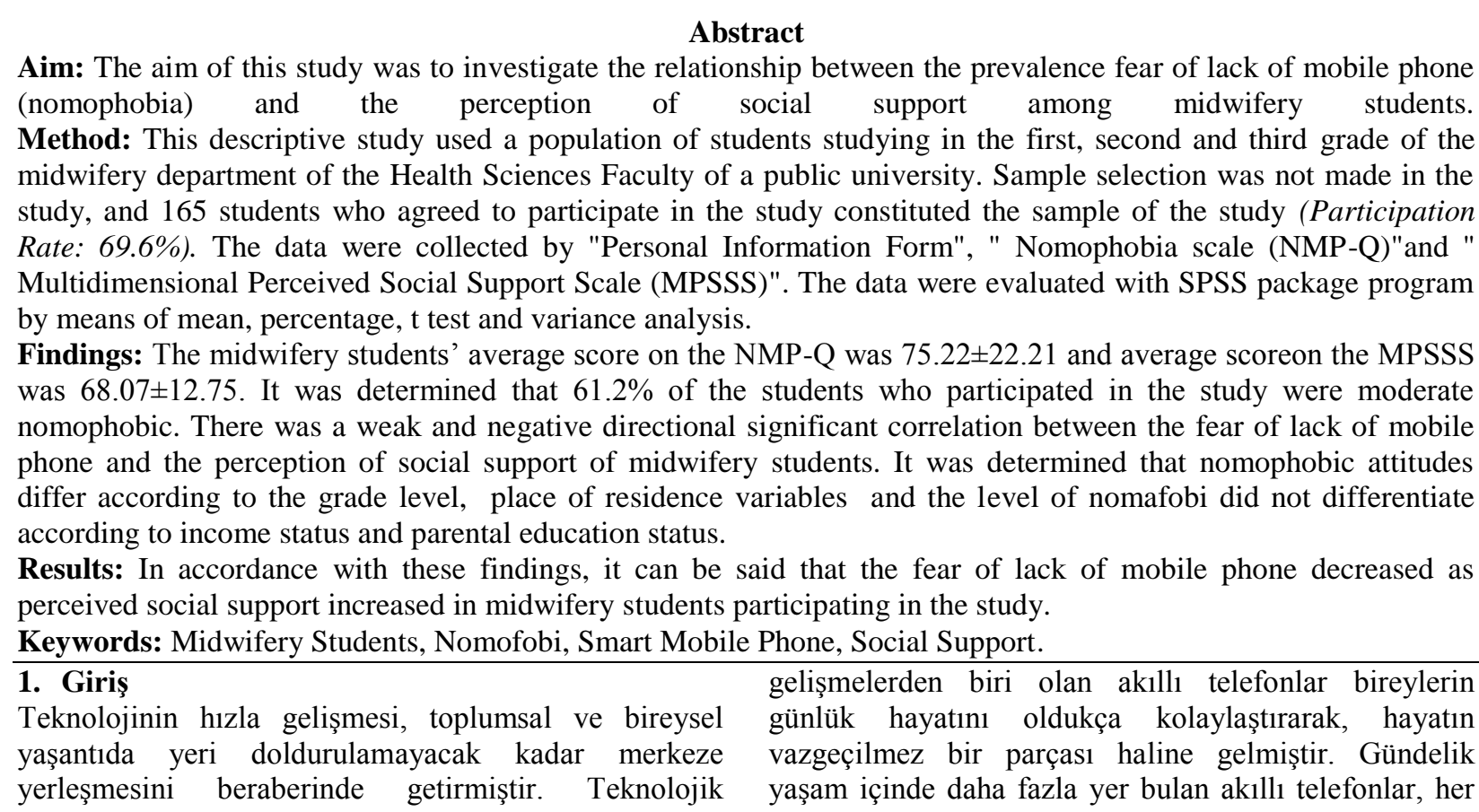


koşulda ve her anda iletişimde olmak ve kalmak, internete bağlanmak, oyun oynamak, film izlemek ve müzik dinlemek, kısaca güzel vakit geçirmek için mecburi bir araç haline dönüşmüştür [1]. Bu fonksiyonlar bireylere; kolay ve hızlı bilgi paylaşımı, iletişim için için zaman ve mesafe bağımlılığın ortadan kaldırması, mekana bağlı kalmadan işlerin yürütülebilmesi gibi gibi hayatı kolaylaştıran birçok eylem kazandırmıştır [2-4].

Akıllı telefonların hayatı kolaylaştırmanın yanında aşırı ve kontrolsüz kullanımı birtakım problemlere neden olabilmektedir. Artan bireysellik ve buna bağlı olarak zayıflayan yüz yüze iletişim, bağımlılık yaratan uygulamalar, depresyon, nomofobi, baş ağrısı, görme bozuklukları, uyku problemleri, kas iskelet problemleri, fizyolojik ve psikolojik sorunları da vurgulayan araştırmalar bulunmaktadır [1,5-10].

Modern çağın yeni fobisi olarak tanımlanan nomofobi, bireyin mobil cihaza erişemediği veya cep telefonu üzerinde iletişim kuramadığında yaşanılan korku olarak tanımlanmaktadır $[11,12]$. No-Mobile-Phone ifadesinin kısaltılarak geliştirildiği "Nomofobi", ayrıca cep telefonuyla temas kuramamaktan kaynaklanan huzursuzluk, kaygı, sinirlilik veya acı olarak da tanımlanabilmektedir [13]. Özellikle genç nesilde çok sık görülen nomofobi çoğunlukla görmezden gelinen bir rahatsızlıktır. Ancak müdahale edilmediği takdirde kişinin akademik, iş ve sosyal yaşantısına ciddi zararlar verebilecek bir duruma dönüşebilmektedir [14].

Bireylerin psikolojik ve fizyolojik sağlıkları için sosyal destek koruyucu bir faktördür. Sosyal destek aynı zamanda başa çıkma yardımcısı" olarak değerlendirilmiştir. Bireyin çevresinden aldığı sosyal desteğin azlığı veya fazlalığı sorunlarla baş etmede önemli bir rol oynamaktadır [15]. Sosyal ilişkileri zayıf olan bireyler kişisel ve çevresel sorunlardan kaçınmak için sanal ortamları daha s1k tercih etmekte ve geçici bir uzaklaşma ile kendisini iyi hissedebilmektedir. Aradıkları ilgiyi sanal dünyada bulan bireyler bu ortama sürekli ulaşmak ve çevrimiçi kalmak isteyebilir [16]. Bu durum ise sanal dünyalarına ulaşamadıkları an nomofobik davranışları beraberinde getirebilir. $\mathrm{Bu}$ bağlamda sosyal ilişkiler nomofobiyi azaltma konusunda anahtar rol oynayabilir.

Öğrenciler tarafından çok amaçlı kullanılan akıllı telefonlar öğrencilerin hayatının merkezinde yer almaktadır [17]. Nitekim, akıllı telefonların ilk kullanıcılarının üniversite öğrencilerinin olduğu ve genç yetişkinlik döneminde akıllı telefon kullanımın popüler olduğu bildirilmektedir $[18,19]$. Bu bağlamda ortaya çıkan nomofobi kavramının genç nüfus arasındaki yaygınlığının incelendiği çalışmalar önem kazanmaktadır. Ayrıca, risk grubunda bulunan öğrencilerin nomofobik tutumlarını etkileyen faktörlerin araştırılmasına ve nomofobinin sosyal ve akademik hayatlarını ne yönde etkilediğine dair çalışmaların yürütülmesine ihtiyaç vardır. Dolayısıyla bu çalışma, ebelik öğrencilerinin mobil telefon yoksunluğu korkusu ile sosyal destek algısı arasındaki ilişkinin incelenmesi amacıyla yapılmıştır.

\section{Gereç Ve Yöntem}

2.1 Araştırmanın Evreni ve Örneklemi: Tanımlayıcı desendeki çalışma 2018-2019 Eğitim Öğretim yılı güz döneminde yürütülmüştür. Araştırmanın evrenini, bir kamu üniversitesinin Sağlık Bilimleri Fakültesi Ebelik Bölümü birinci ve ikinci, üçüncü sınıfında öğrenim gören öğrenciler oluşturdu. Çalışmada örneklem seçimine gidilmemiş olup çalışma yürütülürken okulda bulunan ve araştırmaya katılmayı kabul eden 165 öğrenci çalışmanın örneklemini oluşturdu (Katılma Oranı: \%69.6)

2.2 Veri Toplama Araçları: Veriler, araştırmacılar tarafindan oluşturulan "Tanıtıcı Bilgi Formu", Nomofobi Ölçeği (NMP-Q)" ve "Çok Boyutlu Algılan Sosyal Destek Ölçeği (ÇBASDÖ)” kullanılarak toplanmıştır.

2.3 Tanıtıcı Bilgi Formu: Araştırmacılar tarafından literatür taranarak geliştirilen form, öğrencilerin sosyodemografik özellikleri, ak1llı telefon kullanma alışkanlıkları ve deneyimlerine ilişkin 22 soru içermektedir.

2.4 Nomofobi Ölçeği (NMP-Q): Yildirim ve Correia (2015) tarafindan geliştirilen ölçeğin Türkçe uyarlaması Yıldırım ve arkadaşları (2016) tarafından yapılmıştır $[12,20]$. Ölçek toplam 20 maddeden oluşmaktadır. Ölçekten alınabilecek minimum puan 20 iken, maksimum puan 140'tır. Ölçek sorularını, 1 puan: kesinlikle katılmıyorum, 7 puan: kesinlikle katılıyorum arasında değerlendirmeleri istenmektedir. Ölçek, bilgiye Erişememe (4 madde), bağlantıyı kaybetme (5 madde), iletişime geçememe ( 6 madde) ve rahat hissedememe (5 madde) olmak üzere 4 alt boyuttan oluşmaktadır. Ölçekten alınan toplam puan yükseldikçe nomofobik tutum artmaktadır. Orijinal ölçeğin Cronbach's alpha kullanılarak hesaplanan güvenirlik katsayısı .95 ve Türkçe'ye uyarlanmış ölçeğin güvenirlik katsayısı ise .92 olarak verilmiştir. Bu çalışma için Cronbach's alpha güvenirlik katsayısı ,76 olarak belirlenmiştir.

2.5 Çok Boyutlu Algılan Sosyal Destek Ölçeği: Zimmet ve arkadaşları (1988) tarafından geliştirilen ölçek, sosyal desteğin yeterliliğini öznel olarak değerlendirmekte ve toplam 12 maddeden oluşmaktadır [21]. Türkçe uyarlaması Eker ve Arkar (2001) tarafından yapılmıştır [22]. Ölçek, aile (3, 4, 8, 11. maddeler), arkadaşlar $(6,7,9,12$. maddeler) ve özel bir insan $(1,2,5,10$. maddeler) olmak üzere üç farklı kaynaktan alınan sosyal desteğin yeterliliğini değerlendirmektedir. Yedili likert tipinde olan ölçekten alınabilecek en düşük puan 4 , en yüksek puan $28^{\prime}$ dir. Elde edilen puanın yüksek olması algılanan sosyal desteğin yüksek olduğunu göstermektedir.

\subsection{Verilerin değerlendirilmesi}

Çalışmadan elde edilen verilerin istatistiksel analizinde SPSS 16.0 paket programı kullanıldı. Verilerin normal dağılıma uygunluğu Kolmogorov-Smirnov testi ile değerlendirildi. Tanımlayıcı istatistiklerin gösteriminde 
ortalama, standart sapma, sayı, yüzdelik, kullanılırken, normal dağılım gösteren verilerin karşılaştırılmasında bağımsız örneklem t-testi, tek yönlü varyans analizi (ANOVA) kullanıldı. Nomofobi ile sosyal destek arasındaki ilişki pearson iki yönlü korelasyon analizi ile değerlendirildi.

2.7 Çalışmanın Etik İlkeleri: Araştırmanın yapıldığg üniversitesinin Sağlık Bilimleri Fakültesi'nden yazılı izin alındı. Araştırmaya dahil edilen öğrencilere çalışma hakkında bilgi verildikten sonra öğrencilerin sözel izinleri alındı. Araştırmaya katılacak öğrencilere, bireysel bilgilerin gizli kalacağı konusunda açıklama yapılıp "gizlilik ilkesine" uyulmuştur.

\section{8 Çalışmanın Sınırlılıkları}

Çalışmanın sınırlılığı sadece bir kamu üniversitesinde öğrenim gören Ebelik Bölümü öğrencileri ile yürütülmesidir. Ayrıca araştırmanın yürütüldüğü üniversitenin 3 yıllık bir akademik hayatı bulunduğu için araştırmada 4. sınıfların olmaması da araştırmanın sinırlılıkları arasında yer almaktadır.

\section{Bulgular}

Araștırmaya katılan öğrencilerin yaş ortalaması 19,98 $\pm 2,07$ (min:18, max:37) olduğu ve \%81.8'nin ebelik bölümünü isteyerek tercih ettiği belirlendi. Ebelik öğrencilerinin, \%40'1 birinci, \%29.7'si ikinci ve \%30.3'ü üçüncü sınıf olduğu belirlendi. Öğrencilerin \%75.2'sinin gelirinin giderine denk olduğu, \%55.2'sinin ailesi ile birlikte kaldığı, \%27,9'unun devlet yurdunda ve $\% 17$ 'sinin ise özel yurtta kaldığı belirlendi.

\begin{tabular}{|c|c|c|c|}
\hline & & $\mathbf{n}$ & $\%$ \\
\hline \multirow[t]{4}{*}{ Akıllı telefon kullanım süresi } & 1 yildan az & 2 & 1,2 \\
\hline & $1-3$ y1l & 42 & 25,5 \\
\hline & $4-6$ y1l & 91 & 55,2 \\
\hline & 7 yıl ve üzeri & 30 & 18,2 \\
\hline \multirow[t]{4}{*}{ Günlük telefon kontrol sıklığı } & $1-16 \mathrm{kez}$ & 49 & 29,7 \\
\hline & $17-32 \mathrm{kez}$ & 61 & 37,0 \\
\hline & $33-49 \mathrm{kez}$ & 33 & 20,0 \\
\hline & 50 ve üzeri & 22 & 13,3 \\
\hline \multirow[t]{3}{*}{ Günlük mobil internet kullanım süresi } & $1-3$ saat & 55 & 33,3 \\
\hline & 4-6 saat & 73 & 44,2 \\
\hline & 7 saat ve üzeri & 37 & 22,4 \\
\hline \multirow[t]{6}{*}{ *Akıllı telefon kullanım amacı } & Gündemi Takip etme & 132 & 80 \\
\hline & Bilgi-Ödev araştırma & 138 & 83,6 \\
\hline & Alışveriş yapma & 75 & 45,5 \\
\hline & Oyun Oynama & 61 & 37 \\
\hline & Sosyal A $\breve{g}$ & 136 & 82,4 \\
\hline & $\begin{array}{l}\text { Müzik dinleme-Film } \\
\text { izleme }\end{array}$ & 127 & 77 \\
\hline \multirow[t]{3}{*}{ Sosyal medyada günlük geçirilen süre } & 1-3 saat & 99 & 60 \\
\hline & 4-6 saat & 55 & 33,3 \\
\hline & 7 saat ve üzeri & 11 & 6,7 \\
\hline \multirow[t]{2}{*}{ Yanında şarj aleti taşıma durumu } & Evet & 49 & 29,7 \\
\hline & Hayır & 116 & 70,3 \\
\hline \multirow[t]{2}{*}{ Uyumadan önce akıllı telefon ile zaman geçirme } & Evet & 117 & 70,9 \\
\hline & Hayır & 48 & 29,1 \\
\hline \multirow[t]{2}{*}{ Akıllı telefonu gece kapatma durumu } & Evet & 39 & 23,6 \\
\hline & Hayır & 126 & 76,4 \\
\hline \multirow[t]{3}{*}{ Uyurken telefonun konumu } & Baş ucunda & 87 & 52,7 \\
\hline & Aynı odada, uzak yerde & 76 & 46,1 \\
\hline & Farklı odada & 2 & 1,2 \\
\hline \multicolumn{4}{|c|}{ 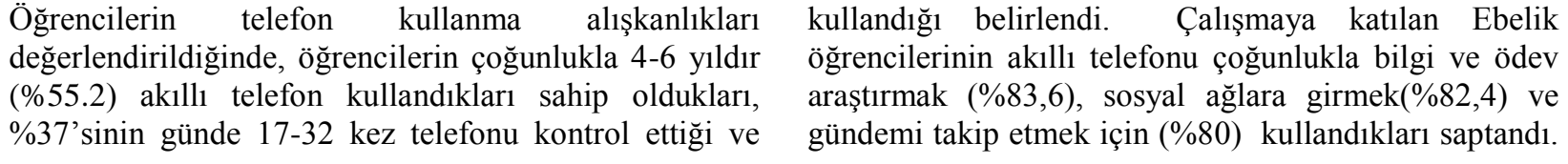 } \\
\hline
\end{tabular}


Öğrencilerin yarından fazlasının sosyal medyada günlük geçirdiği süre 1-3 saat (\%60), \%70.9'u uyumadan önce telefonu ile vakit geçirdiği ve \%52.7'sinin ise telefonunu uyurken baş ucunda konumlandırdığ belirlendi (Tablo 1).

Tablo 2. Öğrencilerin Nomofobi Ölçeği ile Çok Boyutlu Algılan Sosyal Destek Ölçeği Toplam Puan ve Alt Boyut Puan Ortalamaları

\begin{tabular}{|l|l|}
\hline & Ort \pm SS \\
\hline Nomofobi Ölçeği Toplam puan & $74,22 \pm 22,21$ \\
\hline $\begin{array}{l}\text { Çok Boyutlu Algılan Sosyal Destek } \\
\text { Ölçeği }\end{array}$ & Ort \pm SS \\
\hline Aile & $24,47 \pm 4,90$ \\
\hline Arkadaşlar & $23,64 \pm 4,56$ \\
\hline Özel Bir İnsan & $19,68 \pm 6,87$ \\
\hline Toplam Puan & $68,07 \pm 12,57$ \\
\hline
\end{tabular}

Ebelik öğrencilerinin NMP-Q toplam puan ortalamas $74.22 \pm 22.21$ olduğu belirlenirken, ÇBASDÖ toplam puan ortalamasının ise $68.07 \pm 12.75$ olduğu saptand (Tablo 2).

Tablo 3.Öğrencilerin Nomofobi Ölçeği Toplam Puan ile Çok Boyutlu Algılan Sosyal Destek Ölçeği'ne Ait Puanlar Arasındaki İlişki

\begin{tabular}{|c|c|c|c|c|c|}
\hline \multicolumn{2}{|c|}{} & Aile & Arkadaşlar & $\begin{array}{c}\text { Özel } \\
\text { İnsan }\end{array}$ & $\begin{array}{c}\text { ÇBASDÖ } \\
\text { Toplam Puan }\end{array}$ \\
\hline \multirow{2}{*}{ NMP-Q } & $\mathbf{r}$ &,$- 541^{* *}$ &,- 295 &, 048 &,- 226 \\
\cline { 2 - 6 } & $\mathbf{p}$ &, 000 &, 000 &, 537 &, 020 \\
\hline
\end{tabular}

Ebelik öğrencilerinin mobil telefon yoksunluğu korkusu ile algilanan sosyal destek ve algilanan sosyal destek alt boyutu olan arkadaşlar ve aile arasında negatif yönlü anlamlı bir ilişki saptandı (Tablo 3).

Öğrencilerin sosyodemografik özelliklerine göre nomofobik tutumları ile değerlendirildiğinde, sınıf düzeyi (f:8,553; p:,000) ve kalınan yer (f:3,211; p:,025) değişkenine göre nomofobik tutumun farklılaştığı belirlendi. Birinci sınıfların diğer sınıflara oranla ve yurtta kalan öğrencilerin ise ailesi ile birlikte kalan öğrencilere oranla anlamlı olarak daha yüksek düzeyde nomofobik olduğu saptandı. Çalışmaya katılan öğrencilerin ebeveyn eğitim durumu (Anne eğitim durumu: f:,510; p:,728; baba eğitim düzeyi: f:,951; $p$ : ,436), bölümü isteyerek tercih etme (t: ,034; p: ,973) ve gelir durumu (f: 2,$864 ; \mathrm{p}:, 060$ ) değişkenlerine göre ise nomofobi düzeyinin farklılaşmadığı belirlendi.

\section{Tartışma}

$\mathrm{Bu}$ çalışmada, mobil telefondan yoksun kalma korkusunun (nomofobi) ebelik öğrencileri arasında yaygınlığı ve sosyal destek algısı arasındaki ilişki araştırılmıştır. Araştırmada Ebelik öğrencilerin orta düzeyde nomofobik olduğu bulgusuna ulaşılmıştır.
Burucuoğlu'nun Meslek Yüksek Okulu öğrencileri ile yaptığı çalışmada da öğrencilerinin yüksek düzeyde nomofobik olduğu, Hakkari'nin yaptığı çalışmada benzer şekilde üniversite öğrencilerinin \%51'nin yüksek düzeyde nomofobik olduğu belirlenmiştir [23,24]. Hoşgör ve arkadaşlarının sağlık yüksekokulu öğrencileri ile yaptıkları çalışmada ise ögrrencilerin orta düzeyde nomofobik oldukları belirlenmiş, Öz ve Tortop ise üniversite öğrencilerinin \%51.7'sinin nomofobik durum açısından riskli olduğunu bildirmiştir $[25,26]$. Nitekim, akıllı telefonların ilk kullanıcıları üniversite öğrencileri olduğu kabul edildiği [18] ve yapılan çalışmalarda üniversite öğrencilerinin nomofobik durum açısından risk altında olduğu [26] göz önünde bulundurulduğunda çalışma sonuçları literatürü destekler niteliktedir.

Öğrencilerin nomofobik tutumları ile algılan sosyal destek arasındaki ilişki incelendiğinde, negatif yönde zayıf düzeyde anlamlı ilișki belirlenmiştir. $\mathrm{Bu}$ çalışmadan farklı olarak Büyükçolpan'ın (2019) çalışmasında algılanan sosyal desteğin nomofobiyi pozitif yönde anlamlı olarak etkilediği bildirilmiştir [16]. Bu sonuç, bireyin diğer insanlarla ilişkisini sürdürebilmesi ve yakınlık kurabilmesi için günümüzde teknolojik cihazları yoğun olarak kullanması ve buna bağlı olarak akıllı telefonuna ulaşamadığında yaşadığı kayg1 ile ilişkilendirilebilir. $\mathrm{Bu}$ çalışmada ise ögrencilerin ailelerinden ve arkadaşlarından algıladıkları sosyal desteğin nomofobik tutumu anlamlı düzeyde etkilediği tespit edilirken, özel insan alt boyutu ile anlamlı ilişki bulunamamıştır. Bu bağlamda, aileden ve arkadaşlardan algılanan sosyal destek artıkça nomofobik tutumun azaldığ 1 söylenebilir. Nitekim, sosyal ilişkileri zayıf olan bireyler olumsuz duygularla baş etmek amacıyla aradıkları ilgi ve desteği sanal dünyada bulabilirler. Bundan dolayı sürekli olarak çevrim içi kalmak isteyebilir ve diledikleri her an sanal dünyalarına ulaşmak isteyebilirler. $\mathrm{Bu}$ durum ise sanal dünyalarına ulaşamadıklarında akılcı olmayan kaygı, korku ve nomofobik davranışları beraberinde getirebilir.

Öğrencileri bazı değişkenlere göre nomofobik tutumları incelendiğinde, sınıf düzeyi ve kalınan yer değişkenine göre nomofobik tutumun farklılaştığı belirlenirken, ebeveyn eğitim durumu, gelir durumu ve bölümü isteyerek tercih etme değişkenlerine göre nomofobi düzeyinin farklılaşmadığı belirlenmiştir. Birinci sınıfların nomofobik tutumunun diğer sınıflara oranla daha yüksek olduğu ve yurtta kalan öğrencilerin ise nomofobik tutumunun ailesi ile birlikte kalan öğrencilere göre daha yüksek olduğu belirlenmiştir. Ailelerinden ilk kez uzak kalan ve yeni girdikleri üniversite ortamına adapte olmaya çalışan birinci sınıfların aileleri ve arkadaşları ile iletişimi sürdürmeye, sosyal medya ve benzeri ağlarda çevrimiçi olmaya daha dikkat ettikleri ve telefonundan uzak kalma ve istedikleri anda istedikleri bilgiye ulaşamama konularında daha endişeli oldukları söylenebilir. Benzer şekilde yurtta kalan öğrencilerin aileleri ile iletişimi sürdürmek konusunda daha kaygılı oldukları 
söylenebilir. Nitekim, Prasa ve ark., (2017) ve Hakkari'nin (2018) araştırma sonuçları, çalışma bulgularını destekler niteliktedir [24,27].

\section{Sonuç ve Öneriler}

Sonuç olarak çalışmaya katılan ebelik öğrencilerinin orta düzeyde nomofobik olduğu ve algilanan sosyal destek artıkça mobil telefondan yoksun kalma korkusunun azaldığı belirlenmiştir. Nomofobiyi azaltma noktasında ailelere ve eğitimcilere büyük sorumluluklar düşmektedir. Üniversitlerde, psikolojik danışma merkezleri aracılığıyla nomofobinin önlenmesine yönelik programlar ve çalışmalar yapılabilir. Ayrıca, öğrencilerin farklı etkinliklerle de zaman geçirebileceği konusunda tüm eğitimciler ve aileler bilinçlendirilmelidir.

\section{Kaynaklar}

1. Şar, A.H, Işıklar, A. Adaptation of problem mobile phone use scale to Turkish. Journal of Human Sciences, 2012, 9(2), 264-275.

2. Hong, F.Y, Chiu, S.I, Huang, D.H. A model of the relationship between psychological characteristics, mobile phone addiction and use of mobile phones by Taiwanese university female students. Computers in Human Behavior, 2012, 28(6), 2152-2159.

3. Park, N, Kee, K.F, Valenzuela, S. Being immersed in social networking environment: Facebook groups, uses and gratifications, and social outcomes. CyberPsychology ve Behavior, 2009, 12(6), 729-733.

4. Yengin, D.A. Sosyal Medya Ve Akıllı Mobil Teknoloji: Akıllı Sosyal Yaşamlar. The Turkish Online Journal of Design, Art and Communication , 2016, 6(2), 105-113.

5. Ming, Z, Pietikainen, S, Hänninen, O. Excessive Texting in Pathophysiology of First Carpometacarpal Joint Arthritis. Pathophysiology, 2006, 13(4), 269-270.

6. Thomée, S, Härenstam, A, Hagberg, M. Mobile phone use and stress, sleep disturbances, and symptoms of depression among young adults-a prospective cohort study. BMC Public Health, 2011, 11(66), 1-11.

7. Augner, C, Hacker, G.W. Associations between problematic mobile phone use and psychological parameters in young adults. International Journal of Public Health, 2012, 57 (2), 437-441

8. Boulianne, S. Social media use and participation: A metaanalysis of current research. Information, Communication ve Society, 2015, 18(5); 524-538.

9. Öztürk, U.C. Bağlantıda Kalmak ya da Kalmamak İște Tüm Korku Bu: İnternetsiz Kalma Korkusu ve Örgütsel Yansimaları. Journal Of International Social Research, 2015 , $8(37)$.

10. Tamura, H, Nishida, T, Tsuji, A, Sakakibara, H. Association between Excessive Use of Mobile Phone and Insomnia and Depression among Japanese Adolescents. International Journal of Environmental Reseach and Public Health, 2017, $14,701$.

11. King, A.L.S, Valença, A.M, Silva, A.C.O, Baczynski, T, Carvalho, M.R, Nardi, A.E. Nomophobia: Dependency on virtual environments or social phobia? Computers in Human Behavior, 2013, 29(1), 140-144.

12. Yildirim, C, Correia, A.P. Exploring the dimensions of nomophobia: Development and validation of a self-reported questionnaire. Computers in Human Behavior, 2015, 49, 130137.

13. Pavithra, M.B, Madhukumar, S. A study on nomophobiamobile phone dependence, among students of a medical college in Bangalore. National Journal of Community Medicine, 2015, 6(3), 340-344.
14. Öz, H. Üniversite Okuyan Genç Yetiskinlerin Mobil Telefon Yoksunluğu Korkusu (Nomofobi) İle Kişilik Tipleri Arasındaki İlişkinin İncelenmesi. İstanbul Aydın Üniversitesi, Psikoloji Anabilim Dalı, İstanbul, 2018.

15. Thoits, P. Stress, Coping, And Social Support Processes: Where are we? What next? Journal of Health and Social Behavior. Extra Issue, 1995, 53-79.

16. Büyükçolpan, H. Üniversite Öğrencilerinde Nomofobi, Bağlanma Biçimleri, Depresyon ve Algılanan Sosyal Destek. Hacettepe Üniversitesi, Eğitim Bilimleri Ana Bilim Dalı. 2019, Ankara.

17. Deshpande, A. Mobile Addiction and Associated Factors Amongst Youth. Indian Journal of Mental Health, 2015, 2(3): 244-248.

18. Lee, S.Y. Examining the Factors That Influence Early Adopters' Smartphone Adoption: The case of college students. Telematics and Informatic, 2014, 31(2), 308-318.

19. Yildirim, C. Exploring the dimensions of nomophobia: Developing and validating a questionnaire using mixed methods research. Graduate Thesesand Dissertations. Lowa State University, 2014. http://lib.dr.iastate.edu/etd/14005 (Accessed 02.11.2018)

20. Yildirim, C, Sumuer, E, Adnan, M, Yildirim, S. A growing fear: Prevalence of nomophobia among Turkish college students. Information Development, 2016, 32(5), 1322- 1331.

21. Zimmet, G.D, Powel, S.S, Farley, G.K. The multidimensional scale of perceived social support. J Pers Assess, 1988, 52, $30-41$.

22. Eker, D, Akar, H. Çok boyutlu algılanan sosyal destek ölçeğinin faktör yapısı, geçerlik ve güvenirliği. Turk Psikol Derg, 1995, 34:45-55.

23. Burucuoğlu, M. Meslek Yüksekokulu Öğrencilerinin Nomofobi Düzeyleri Üzerinde Bir Araștırma. Karabük Üniversitesi Sosyal Bilimler Enstitüsü Dergisi, 2017, 7(2), 482-489

24. Hakkari, F. Meslek Yüksekokulu Öğrencilerinin Nomofobi Düzeylerinin Belirlenmesi: Kırıkhan MYO Örneği. Atlas International Referred Journal On Social Sciences, 2018, 4(10), 786-797.

25. Hoşgör, H, Koç, Tütüncü, S, Gündüz, Hoşgör, D, Tandoğan, Ö. Üniversite Öğrencileri Arasında Sosyal Medyadaki Gelişmeleri Kaçırma Korkusu Yaygınlığının Farklı Değişkenler Açısından İncelenmesi. International Journal of Academic Value Studies, 2017, 3(17), 213-223.

26. Öz, H, Tortop, H.S. Üniversite Okuyan Genç Yetişkinlerin Mobil Telefon Yoksunluğu Korkusu (Nomofobi) İle Kișilik Tipleri Arasındaki İlişkinin İncelenmesi. Yeni Medya Elektronik, 2018, 2(3), 146-159.

27. Prasa, M, Patthi, B, Singla, A, Gupta, R, Saha, S, Kumar, J.K, Pandita, V. Nomophobia: A Cross-Sectional Study to assess Mobile Phone Usage Among Dental Students, Journal of Clinical and Diagnostic Research, 2017, 11(2), ZC34.

http://edergi.cbu.edu.tr/ojs/index.php/cbusbed isimli yazarın CBU-SBED başlıklı eseri bu Creative Commons Alınt1Gayriticari4.0 Uluslararası Lisansı ile lisanslanmıştır. 